Case Reports in
Gastroenterology
Case Rep Gastroenterol 2021;15:431-435

DOI: 10.1159/000511006
Published online: April 19, 2021

(C) 2021 The Author(s)

Published by S. Karger AG, Basel

www.karger.com/crg

This article is licensed under the Creative Commons Attribution-NonCommercial 4.0 International License (CC BY-NC) (http://www.karger.com/Services/OpenAccessLicense).

Usage and distribution for commercial purposes requires written permission.

\title{
Congenital Lumbar Hernia in an 8-Month-Old Boy
}

\author{
Mohamed Mansy ${ }^{\mathrm{a}} \quad$ Mostafa Kotb $^{\mathrm{b}}$ Mohamed Abouheba ${ }^{\mathrm{b}}$ \\ aPediatric Surgery, Port Said Faculty of Medicine, Port Said, Egypt; bPediatric Surgery, \\ Alexandria Faculty of Medicine, Alexandria, Egypt
}

\section{Keywords}

Lumbar hernia $\cdot$ Lumbar triangle $\cdot$ Case report

\begin{abstract}
Congenital lumbar hernias are uncommonly seen in the pediatric age group, with only about 60 cases reported in the literature. It is usually accompanied by a multitude of congenital anomalies involving different organ systems of the body. For instance, it may involve the ribs, spine, muscles, and the kidneys. Herein, we report a case of congenital lumbar hernia in an 8month-old boy who underwent an operative repair using a mesh with an uneventful outcome.

(C) 2021 The Author(s)

Published by S. Karger AG, Basel

\section{Introduction}

Congenital lumbar hernias are uncommonly seen in infants and children, with only about 60 cases reported in the English literature [1]. Around two-thirds of the cases have other congenital anomalies, where the lumbocostovertebral syndrome is the most common association. Other associated anomalies include caudal regression syndrome, ureteropelvic junction obstruction, and renal agenesis [2]. Herein, we report a case of congenital lumbar hernia involving the superior lumbar triangle in an 8-month-old boy who underwent an operative repair with an uneventful postoperative course.
\end{abstract}

\begin{tabular}{ll}
\hline & Mostafa Kotb \\
& Pediatric Surgery Unit \\
& Alexandria Faculty of Medicine \\
& 21 Champlion St, Azarita, Alexandria 21615 (Egypt) \\
mostafa.rashad@alexmed.edu.eg
\end{tabular}




\section{Case Reports in Gastroenterology}

Case Rep Gastroenterol 2021;15:431-435 DOI: 10.1159/000511006

Mansy et al.: Congenital Lumbar Hernia in an 8-Month-Old Boy

\section{Case Report/Case Presentation}

An 8-month-old boy presented to our department with a gradually enlarging mass in the left lumbar region since birth. His parents reported that this mass increases with crying and coughing and disappears during sleeping. On examination, a large lumbar swelling on the left side, measuring around $10 \times 7 \mathrm{~cm}$, was evident. Reduction of this mass unmasked a huge fascial defect involving the whole layers (shown in Fig. 1). The rest of the examination was unremarkable. Therefore, the diagnosis of congenital lumbar hernia was confirmed. Plain X-ray images for thoracic cage and spine to exclude lumbocostovertebral syndrome and abdominal ultrasound to exclude renal anomalies were performed.

A left transverse lumbar incision along the skin crease with opening of skin and superficial fascia was performed. Exploration revealed a huge lumbar defect occupying the whole layers, around $12 \times 8 \mathrm{~cm}$ in dimensions, extending from the costal margin superiorly to the iliac crest inferiorly and the posterior border of the external oblique anteriorly to the quadratus lumborum muscle posteriorly. Closure of the fascial defect by interrupted figure-of- 8 tension stitches using vicryl $3 / 0$ was done followed by muscle closure using interrupted simple stitches between the anterior abdominal wall aponeurosis and the quadratus lumborum. As the defect is large, an on-lay mesh repair using Ultrapro mesh, a partially absorbable lightweight mesh, was done and fixed all around by vicryl 3/0 sutures (shown in Fig. 2). The postoperative course was uneventful.

\section{Discussion/Conclusion}

The lumbar region is an exceedingly rare site of herniation in infants and children. This region is divided into 2 triangles: superior and inferior. The superior triangle is bounded by the inferior aspect of the last rib, the internal oblique and the quadratus lumborum, while the inferior one is bounded by the origin of the external oblique, latissimus dorsi, and the iliac crest [3]. In our case, herniation was present in the superior triangle, which is the most common site of lumbar herniation.

Touloukian [4] proposed that a somatic mutation during early embryogenesis, possibly resulting from transient anoxia, is the most probable cause. Consequently, derangement of the lumbar muscles and aponeuroses occur, leading to herniation. This explains the high incidence of associated musculoskeletal abnormalities involving the vertebral bodies, ribs, and trunk musculature [4]. In a review conducted by Rattan et al. [5], all of the cases presented with lumbocostovertebral syndrome along with other associated anomalies. Because of these associations, it is mandatory to rule them out by radiographs of the chest and lumbar spine as well as renal tract ultrasound [6].

Optimal surgical intervention is early operative repair to prevent incarceration [7]. Primary closure of the defect is preferred; however, this may not always applicable. On the other hand, large defects like our case require prosthetic mesh repair [8]. Laparoscopic repair with free fascia lata graft reinforcement is reported as well [9]. Fortunately, these large defects are relatively uncommon, and in a study by Wakhlu and Wakhlu [10], only 3 out of 9 patients required mesh repair.

\section{Karger'=}




\section{Case Reports in Gastroenterology}

\section{Statement of Ethics}

The Institutional Review Board of Alexandria University approved this case study. Written informed consent for publication including images was obtained from the patient's parents. Research was conducted ethically in accordance with the World Medical Association Declaration of Helsinki.

\section{Conflict of Interest Statement}

The authors declare no financial disclosures or conflicts of interest.

\section{Funding Sources}

There were no funding sources.

\section{Author Contributions}

M. Mansy and M. Abouheba made and confirmed the diagnosis, provided the details of the case, and contributed to the design of the report. M. Kotb drafted the manuscript. All authors read and approved the final version of the manuscript.

\section{References}

1 Akçora B, Temiz A, Babayiğit C. A different type of congenital lumbar hernia associated with the lumbocostovertebral syndrome. J Pediatr Surg. 2008 Jan;43(1):e21-3.

2 Sengar M, Manchanda V, Mohta A, Jain V, Das S. Intercostal variant of lumbar hernia in lumbocostovertebral syndrome: our experience with 6 cases. J Pediatr Surg. 2011 Oct;46(10):1974-7.

3 Guillem P, Czarnecki E, Duval G, Bounoua F, Fontaine C. Lumbar hernia: anatomical route assessed by computed tomography. Surg Radiol Anat. 2002 Feb;24(1):53-6.

4 Touloukian RJ. The lymbocostovertebral syndrome: a single somatic defect. Surgery. 1972 Feb;71(2):17481.

5 Rattan KN, Agarwal A, Dhiman A, Rattan A. Congenital lumbar hernia: a 15-year experience at a single tertiary centre. Int J Pediatr. 2016;2016:7162475.

6 Krishnamurthy S, Kapoor S. An incomplete form of lumbocostovertebral syndrome in association with atrial septal defect, arthrogryposis and clubfeet. Indian J Pediatr. 2009 Apr;76(4):411-3.

7 Hancock BJ, Wiseman NE. Incarcerated congenital lumbar hernia associated with the lumbocostovertebral syndrome. J Pediatr Surg. 1988 Aug;23(8):782-3.

8 Sharma A, Pandey A, Rawat J, Ahmed I, Wakhlu A, Kureel SN. Congenital lumbar hernia: 20 years' single centre experience. J Paediatr Child Health. 2012 Nov;48(11):1001-3.

9 Morita K, Miyano G, Nouso H, Fukumoto K, Yamoto M, Miyake H, et al. Laparoscopic repair for a congenital lumbar hernia with free fascia lata graft reinforcement. J Pediatr Surg Case Rep. 2014;2(3):101-3.

10 Wakhlu A, Wakhlu AK. Congenital lumbar hernia. Pediatr Surg Int. 2000;16(1-2):146-8. 
Case Reports in Gastroenterology
Case Rep Gastroenterol 2021;15:431-435

DOI: 10.1159/000511006

(c) 2021 The Author(s). Published by S. Karger AG, Basel www.karger.com/crg

Mansy et al.: Congenital Lumbar Hernia in an 8-Month-Old Boy
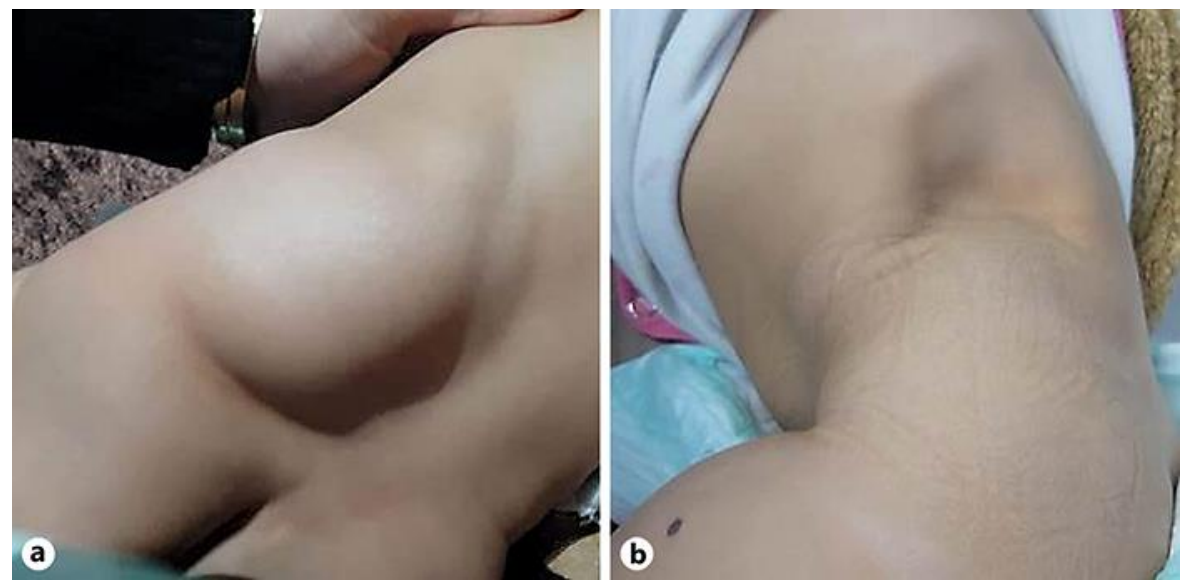

Fig. 1. Clinical examination of the patient. a A well-defined soft tissue mass in the left lumbar region. b Reduction of the mass revealed a huge defect involving all layers. 

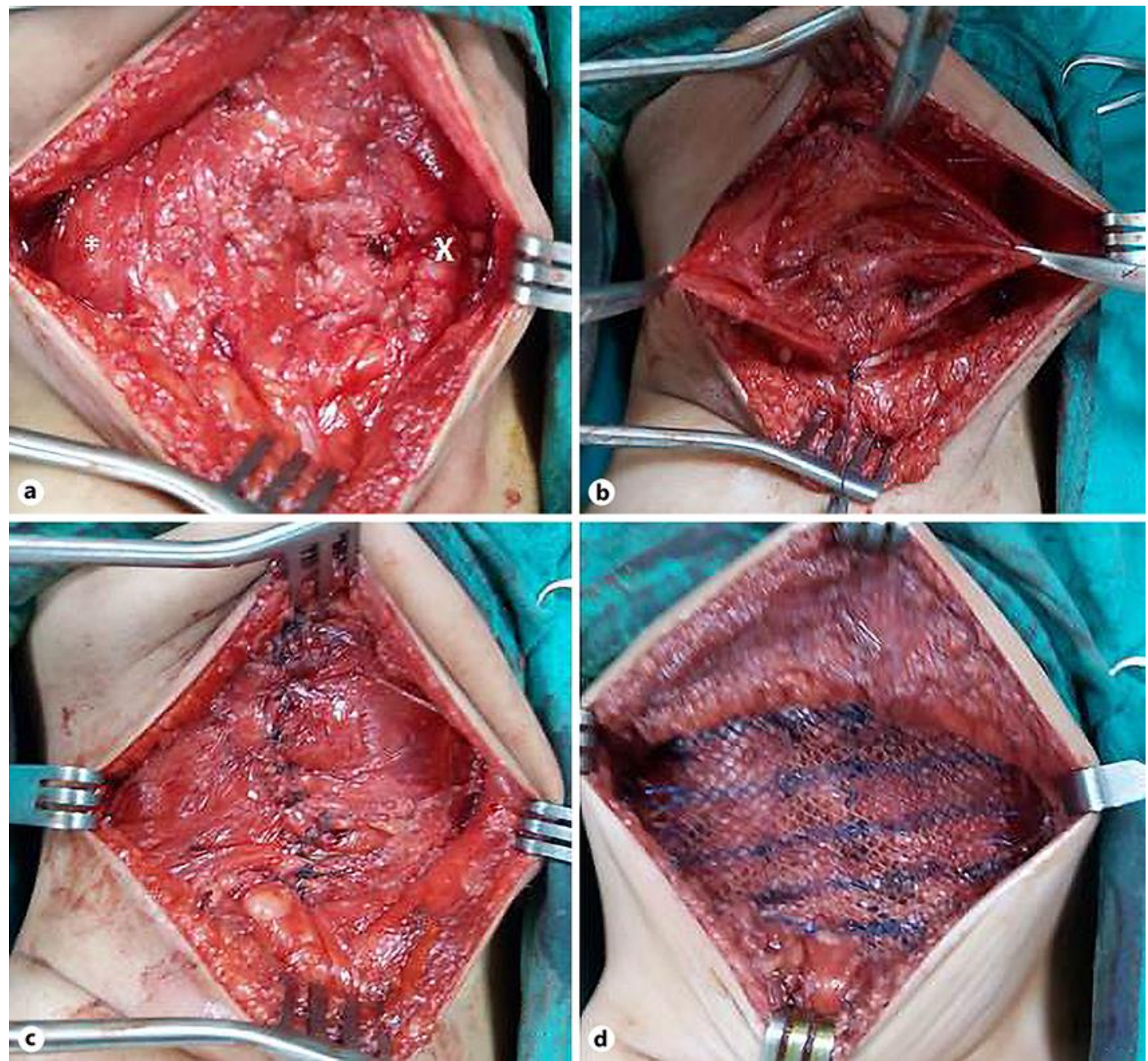

Mansy et al.: Congenital Lumbar Hernia in an 8-Month-Old Boy www.karger.com/crg

Fig. 2. Intraoperative photos. a, b A fascial defect between the posterior border of the external oblique anteriorly $(x)$ and quadratus lumborum $(*)$ posteriorly. c Plication of the fascial defect. $\mathbf{d}$ On-lay mesh repair using Ultrapro mesh. 